\title{
Transition from gaseous compounds to aerosols in Titan's atmosphere
}

\author{
Sébastien Lebonnois, \\ E. L. O. Bakes, \\ and Christopher P. McKay \\ NASA Ames Research Center, MS 245-3, Moffett Field, California 94035-1000
}

Icarus

First submission: September 26, 2001

Revised version: March 21, 2002

Second revision: May 13, 2002 


\begin{abstract}
We investigate the chemical transition of simple molecules like $\mathrm{C}_{2} \mathrm{H}_{2}$ and $\mathrm{HCN}$ into aerosol particles in the context of Titan's atmosphere. Experiments that synthesize analogs (tholins) for these aerosols can help understand and constrain these polymerization mechanisms. Using information available from these experiments, we suggest chemical pathways that can link simple molecules to macromolecules, that will be the precursors to aerosol particles: polymers of acetylene and cyanoacetylene, polycyclic aromatics (PAHs), polymers of HCN and other nitriles, and polyynes. Although our goal here is not to build a detailed kinetic model for this transition, we propose parameterizations to estimate the production rates of these macromolecules, their $\mathrm{C} / \mathrm{N}$ and $\mathrm{C} / \mathrm{H}$ ratios, and the loss of parent molecules $\left(\mathrm{C}_{2} \mathrm{H}_{2}, \mathrm{HCN}, \mathrm{HC}_{3} \mathrm{~N}\right.$ and other nitriles, $\mathrm{C}_{6} \mathrm{H}_{6}$ ) from the gas phase to the haze. We use a 1-dimensional photochemical model of Titan's atmosphere to estimate the formation rate of precursors macromolecules. We find a production zone slightly lower than $200 \mathrm{~km}$ altitude with a total production rate of $4 \times 10^{-14} \mathrm{~g} \mathrm{~cm}^{-2} \mathrm{~s}^{-1}$ and a $\mathrm{C} / \mathrm{N} \simeq 4$. These results are compared with experimental data, and to microphysical models requirements. The Cassini/Huygens mission will bring a detailed picture of the haze distribution and properties, that will be a great challenge for our understanding of those chemical processes.
\end{abstract}

Keywords: Titan; Photochemistry; Organic chemistry; Atmospheres, Composition.

\title{
1 Introduction
}

The dense atmosphere of Titan is composed of approximately 98\% nitrogen molecules and $2 \%$ methane. Photochemistry occuring in this atmosphere yields a suite of other gaseous compounds, including hydrocarbons and nitriles (e.g. ethane, hydrogen cyanide). An aerosol layer, which hides Titan's surface in visible light, is also present in the stratosphere. The composition of the gas and the microphysics of the haze have been studied through observations (both ground-based and from the Voyager spacecrafts) and modeling. But the formation of this haze, from photochemical processes in the gas phase to the smallest aerosol particles considered in the microphysical models (which we will call "precursors"), is not well understood. Photochemical models (Yung et al., 1984; Toublanc et al., 1995; Lara et al., 1996; Lebonnois et al., 2001) do not follow the fate of gaseous compounds with more than 6 heavy atoms $(\mathrm{C}$ and $\mathrm{N}$ ), while microphysical models (McKay et al., 1989; Toon et al., 1992; Rannou et al., 1995, 1997) assume the existence of small particles (of radius around $13 \AA$ ) as the source of material, then follow the microphysical evolution of the particles while conserving mass. Only one work has been done to detail the chemistry of hydrocarbons up to $\mathrm{C}_{60}$ macromolecules (Dimitrov and Bar-Nun, 1997), but this work does not include N-bearing species, and has not yet been applied to simulate Titan's atmospheric composition. In Dimitrov and BarNun (1999), the authors present a model of the agglomeration of aerosols that uses this study. Their model can well reproduce the laboratory synthesis of aerosol particles from Bar-Nun et al. (1988). It was also applied to describe a possible scenario for the synthesis of Titan's aerosols, but no direct comparison was made with observations or with other detailed microphysical models (e.g. Toon et al., 1992; Rannou et al., 1995, 1997).

In this paper, we address the question of how to link photochemical models to microphysical models in a simple, parameterized way, without including a detailed kinetic model to describe all reactions involved in the macromolecules formation. In order to couple these two kind of models, it is necessary to quantify the production rate of precursors from photochemical reactions, and to evaluate the chemical loss of gas phase molecules to the haze. This does not concern the possible condensation of gas phase molecules on aerosol particles in the low stratosphere and troposphere (typically 40 to $150 \mathrm{~km}$ altitude). This is a problem that needs to be treated in the microphysical models, and that does not affect the source function of the haze. In the microphysical models, no addition of mass from the gas phase is considered, which means that chemical growth of macromolecules with addition of gas phase small molecules (e.g. $\mathrm{C}_{2} \mathrm{H}_{2}, \mathrm{HCN}, \mathrm{HC}_{3} \mathrm{~N}$ ) is assumed negligible when the smallest aerosol particles are considered. We will call this transition the precursor level.

The principles adopted in this paper are the following: 
- given a set of chemical species included in the photochemical model, the production of aerosols occurs through a set of initial reactions that will produce the first of the heavy molecules (not included in the photochemistry). These molecules will irreversibly yield aerosol material. Meanwhile, the growth of these macromolecules is a sink for gas phase molecules included in the photochemistry (e.g. $\left.\mathrm{C}_{2} \mathrm{H}_{2}, \mathrm{HCN}, \mathrm{HC}_{3} \mathrm{~N}\right)$.

- during the initial steps of aerosol formation, the macromolecules grow from the first heavy molecules by including small gas phase molecules. Nucleation eventually occurs. Particles grow in mass and radius through several processes: chemical additions (chemical activity continues after nucleation), transition of gas phase macromolecules to the condensed phase, coagulation. By the time the particles reach a radius of approximately $1-2 \mathrm{~nm}$, microphysical considerations suggest that the further coagulation of particles occurs at constant mass, i.e. the addition of mass from the small gas phase molecules has become negligible. We define the precursor level as the transition between the regime where chemical addition of small molecules is significant and the regime where microphysical processes conserving the overall mass of aerosol material dominate. The source function used by microphysical models is the mass flux of aerosol material through this transition.

- this aerosol material, at the precursor level, is composed of macromolecules that have a certain mean length, i.e. that have incorporated, in average, a certain number of gas phase molecules during their chemical growth.

Based on these principles, we estimate the source function of precursors and their bulk elemental composition through these steps, using three sets of parameters:

- we propose three pathways for the initial reactions and the growth of macromolecules (polymers of $\mathrm{C}_{2} \mathrm{H}_{2}$ and $\mathrm{HC}_{3} \mathrm{~N}$, PAHs that may include $\mathrm{HCN}$ and $\mathrm{HC}_{3} \mathrm{~N}$, and polymers of $\mathrm{HCN}$ and nitriles). These propositions are based on experimental results published by several teams (see Table I).

- the reaction rate coefficients $\left(k\right.$, in $\left.\mathrm{cm}^{3} \mathrm{~s}^{-1}\right)$ for these initial reactions are a first set of parameters.

- for each pathway, we propose gas phase molecules that may be incorporated in these macromolecules. The proportions of each molecule in the global macromolecule are controlled by a second set of parameters.

- the yield limiting the growth of a macromolecule (precursor level) is parameterized by the mean number of gas phase molecules incorporated in one macromolecule. We also refer to this parameter as the 'length' of the polymers.

- the mass flux of aerosol material at the precursor level (i.e. the source function of the aerosols) is equal to the product between the mean molecular mass of macromolecules and the production rates of the first heavy molecules (initial reactions).

Laboratory experiments have synthesized tentative analogs to Titan's aerosols, in order to obtain their properties. The study of these products have yielded some hints about the structure of the constituent macromolecules of the tholin particles, and in some cases the $\mathrm{C} / \mathrm{N}$ and $\mathrm{C} / \mathrm{H}$ ratios (Table I). How close tholins represent Titan's aerosols is in debate, but still, understanding the process which makes tholins can certainly help. Using these experiments, we have identified three possible pathways leading from parent molecules $\left(\mathrm{C}_{2} \mathrm{H}_{2}, \mathrm{HCN}, \mathrm{HC}_{3} \mathrm{~N}\right.$ and other nitriles, $\left.\mathrm{C}_{6} \mathrm{H}_{6}\right)$ to macromolecules that will be the building blocks of the precursors. These pathways are described in Section 2. In Section 3, the parameterization of these pathways is detailed, and quantities of interest (mass production rates of the different channels, loss of the parent molecules, $\mathrm{C} / \mathrm{N}$ and $\mathrm{C} / \mathrm{H}$ ratios) can be evaluated. This model is then applied to the atmosphere of Titan in Section 4.

\section{Information from experiments}

Numerous experiments have been done in order to synthesize tholins, analogs for Titan's aerosols. The conditions in the laboratories have been varied while trying to get as near to conditions in 
Titan's atmosphere as possible. Table I presents a summary of these experiments, with some results on the products' analysis. Since the optical properties of tholins provide good matches to the properties of Titan's haze (Khare et al., 1984; Sagan et al., 1992), it is reasonable to assume that the production processes for tholins are close to those occuring in Titan's atmosphere. Most of the $\mathrm{C} / \mathrm{N}$ ratios measured in the tholins are low (between 1.5 and 11), so we expect a fairly important amount of nitrogen to be incorporated in the macromolecules during the chemical processes.

Table I: Experiments of laboratory synthesis of Titan's aerosols' analogs

\begin{tabular}{|c|c|c|c|c|c|c|c|c|}
\hline Papers & $E S^{(a)}$ & $T(K)$ & $\mathrm{p}(\mathrm{mb})$ & Initial gas mix & $\mathrm{Gas}(\mathrm{b})$ & Aerosol particles & $\mathrm{C} / \mathrm{N}$ & $\mathrm{C} / \mathrm{H}$ \\
\hline Khare et al., 1984 & $\mathrm{D}$ & 300 & 0.2 & $90 \% \mathrm{~N}_{2}, 10 \% \mathrm{CH}_{4}$ & - & tholins & & \\
\hline Sagan et al, 1984 & $\mathrm{D}$ & 300 & $>10$ & $90 \% \mathrm{~N}_{2}, 10 \% \mathrm{CH}_{4}$ & - & tholins & 2 & 0.6 \\
\hline Bar-Nun ct all, 1988 & UV & 300 & 270 & $\begin{array}{l}\text { Ar, } 5 \% \mathrm{O}_{2} \mathrm{H}_{2} \\
\text { Ar, } 5 \%\end{array}$ & - & $\begin{array}{l}\text { polyO } \mathrm{y}_{2} \mathbf{H}_{2} \\
\text { polyO2 }\end{array}$ & & \\
\hline Thompson ct al., 1991 & $\mathrm{OP}$ & 300 & 17 & $\begin{array}{l}\mathrm{Ar}, 5 \% \mathrm{HON} \\
90 \% \mathrm{~N}_{2}, 10 \% \mathrm{CH}_{4}\end{array}$ & $\bar{x}$ & $\begin{array}{l}\text { polyHCN } \\
\text { tholins }\end{array}$ & & \\
\hline Scatterwood th at. 1992 & UV & 300 & $\begin{array}{l}0.24 \\
73\end{array}$ & $\begin{array}{l}\mathrm{N}_{2}, 2 \% \mathrm{C}_{2} \mathrm{H}_{2} \\
\mathrm{~N}_{2}, 2 \% \mathrm{C}_{2} \mathrm{H}_{4} \\
\mathrm{He}, 2 \% \mathrm{HCN} \\
\mathrm{Mix}\end{array}$ & $\begin{array}{l}- \\
- \\
-\end{array}$ & 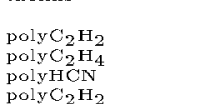 & & \\
\hline McDonald et tal., 1994 & $\mathrm{OP}$ & 300 & 1 & $90 \% \mathrm{~N}_{2}, 10 \% \mathrm{CH}_{4}$ & - & tholins & 1.5 & 0.6 \\
\hline Coll ot at., 1995 & $\mathrm{D}$ & 150 & 900 & $90 \% \mathrm{~N}_{2}, 10 \% \mathrm{CH}_{4}$ & $\mathrm{x}$ & tholins & 11 & 1 \\
\hline McKay, 1996 & $\mathrm{D}$ & 300 & 1000 & $90 \% \mathrm{~N}_{2}, 10 \% \mathrm{CH}_{4}$ & & tholins & 5.5 & 1 \\
\hline Clarke and Ferris, 1997 & UV & 300 & 330 & $90 \% \mathrm{C}_{2} \mathrm{H}_{2}, 10 \% \mathrm{HC}_{3} \mathrm{~N}$ & - & poly $\mathrm{y}_{2} \mathrm{H}_{2} / \mathrm{HC}_{3} \mathrm{~N}^{-}$ & 6.4 & 1.6 \\
\hline Coll ot at., 1999 & $\mathrm{CP}$ & 150 & 2 & $98 \% \mathrm{~N}_{2}, 2 \% \mathrm{CH}_{4}$ & $\mathrm{x}$ & tholins (polyHCN?) & 2.8 & 0.8 \\
\hline Khare ef al, 2001 & $\mathrm{D}$ & 300 & 71 & $90 \% \mathrm{~N}_{2}, 10 \% \mathrm{CH}_{4}$ & $\mathrm{x}$ & tholins & & \\
\hline
\end{tabular}

(a) Energy Source: D = discharge, CP = cold plasma, UV = ultraviolet light

(b) An " $\mathrm{X}$ " in this column indicates that the composition of the resulting gas phase has been studied.

We used the information provided by these experiments to identify several pathways from gas molecules to aerosol particles. Possible pathways that we will analyse in this paper include different kinds of polymers $\left(\mathrm{C}_{2} \mathrm{H}_{2}, \mathrm{HC}_{3} \mathrm{~N}, \mathrm{HCN}\right)$, polyynes and cyanopolyynes and aromatics (PAHs).

Polymers of $\mathrm{C}_{2} \mathrm{H}_{2}$ and $\mathrm{HC}_{3} \mathrm{~N}$

These are obtained by polymerization of acetylene, or of a mixture of acetylene and cyanoacetylene. One possible structure for these polymers is described in Clarke and Ferris, 1997. Clarke and Ferris also indicate the incorporation of other molecules in these polymers $\left(\mathrm{CH}_{4}, \mathrm{C}_{2} \mathrm{H}_{6}, \mathrm{CO}\right)$, but it seems to be of second order. This incorporation should also occur in the case of Titan's atmosphere, but we will restrict our study to acetylene and cyanoacetylene only as a first approximation.

Polyaromatics

Polyaromatic compounds have been detected in laboratory tholins from the Khare et al. (1984) experiment (Sagan et al., 1993; Khare et al., 2001). Previous theoretical work has investigated the growth of the PAHs from benzene by addition of acetylene (Wang and Frenklach, 1994; Wong et al., 2000; Bauschlicher and Ricca, 2000). Nitrogen atoms could be incorporated in the cycles through the addition of $\mathrm{HCN}$ or $\mathrm{HC}_{3} \mathrm{~N}$ instead of acetylene (Ricca et al., 2001). Reaction rates and pathways for this growth are mostly studied at high temperatures (combustion), but some studies cover as low as room temperature, which can allow a tentative extrapolation for Titan's atmospheric conditions $(100-200 \mathrm{~K})$.

Polymers of HCN

Coll et al. (1999) report that polymers of HCN could be part of the tholins they produced. In this experiment, as well as in other similar experiments (Thompson et al., 1991; McDonald et al., 1994), nitrogen has to be incorporated in large quantities to get the observed low $C / N$ ratio, and the obvious candidate is $\mathrm{HCN}$, considering that it is the dominant N-bearing compound (other than $\mathrm{N}_{2}$ ) in the gas phase. The question is, in these experiments, what exactly is produced? HCN could be incorporated as a copolymer in an aliphatic polymer, together with $\mathrm{C}_{2} \mathrm{H}_{2}$ and $\mathrm{HC}_{3} \mathrm{~N}$ (but we are unaware of any possible structure), or it could polymerize on its own. Matthews (1992) presents a study of these polymers, and Minard et al. (1998) discuss possible structures for their formation. Thompson and Sagan (1989) propose another possible structure for a more general polymerization of nitriles.

\section{Polyynes and cyanopolyynes}

The structure of these molecules is $\mathrm{A}-(\mathrm{C} \equiv \mathrm{C})_{n}-\mathrm{B}$, with $\mathrm{A}$ and $\mathrm{B}$ being either $\mathrm{H}$ or $\mathrm{CN}$. Many members of this group have been detected in the gaseous products (Coll et al., 1995; 1999). Only $\mathrm{C}_{2} \mathrm{H}_{2}, \mathrm{HC}_{3} \mathrm{~N}$, and $\mathrm{C}_{4} \mathrm{H}_{2}$ have been observed in Titan's atmosphere. $\mathrm{C}_{4} \mathrm{~N}_{2}$ has also been detected as a solid in the polar atmosphere of Titan. The $\mathrm{C} / \mathrm{N}$ and $\mathrm{C} / \mathrm{H}$ ratios in these compounds are high: the number of $\mathrm{C}$ atoms grows with the length of the molecule, while the number of $\mathrm{H}$ and/or $\mathrm{N}$ atoms is only 1 or 2 . Their fate in Titan's atmosphere can be photolysis to smaller 
compounds, condensation in the low stratosphere, or incorporation in the aerosols. Since the C/N ratios available in the experiments are rather low (the largest is 11, in Coll et al., 1995) and the $\mathrm{C} / \mathrm{H}$ ratios are all around 1 , the polyynes and cyanopolyynes formation and incorporation may not be a dominant growth mechanism for experimental tholins. Despite the difference between the pressures used in experiments and the pressures in the atmosphere of Titan (in the [200-600] $\mathrm{km}$ range in altitude), we assume here that these products are also of second order in the constitutive material of aerosol precursors.

Whether the products obtained in the experiments are long chains or aromatics, or a mix of both, is in debate. In this paper, we will concentrate on the first three mechanisms: polymerization of a mixture of acetylene and cyanoacetylene (polymer 1); PAHs' growth from addition of acetylene on benzene rings (polymer 2, which could incorporate some $\mathrm{HCN}$ and $\mathrm{HC}_{3} \mathrm{~N}$ ); and the polymerization of hydrogen cyanide and other nitriles (polymer 3). We will assume that the tholins and Titan's aerosols are mainly a mixture of these types of macromolecules, to first order.

\section{Parameterization of polymer formation}

In this section, we will discuss the proposed mechanisms for polymer growth, and the necessary assumptions that we had to make. In each case a set of parameters will be isolated. These are summarized in Table II. For each pathway, initial reactions are detailed. Their rate coefficients $\left(k\right.$, in $\left.\mathrm{cm}^{3} \mathrm{~s}-1\right)$ are the first parameters. Once these reactions occured, the products are assumed to ultimately be incorporated in precursor particles. The parameters $(\alpha, \beta, \gamma)$ characterize the proportions of each small molecule that is incorporated in the global macromolecule. The macromolecules grow through addition of these small molecules until they reach the precursor level. These parameterizations allow us to calculate the mass production rates, the $\mathrm{C} / \mathrm{N}$ and $\mathrm{C} / \mathrm{H}$ ratios, and also the incorporation rates of the parent molecules $\left(\mathrm{C}_{2} \mathrm{H}_{2}, \mathrm{HCN}, \mathrm{HC}_{3} \mathrm{~N}\right.$ and other nitriles $)$.

\subsection{Acetylene polymer (polymer 1)}

The exact structure of the polymers of acetylene, or of a mixture of acetylene and cyanoacetylene (Bar-Nun et al., 1988; Clarke and Ferris, 1997), is not well known. It could be chains of double bonds $\mathrm{C}=\mathrm{C}$, as proposed by Clarke and Ferris (1997), a family called vinylacetylenes (VA) in Dimitrov and Bar-Nun (1997). As a mechanism to their formation, a possibility is the attack of the triple bond in either acetylene or cyanoacetylene by a radical site at the end of the chain:

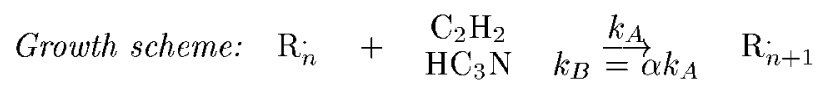

where $\mathrm{R}_{n}$ represents an intermediate step in the polymerization process. Its structure is shown in Fig. 1. This mechanism is reported as dominant for the growth of the VA family in the context of the model developed by Dimitrov and Bar-Nun (1997). The rates $k_{A}$ and $k_{B}$ are not known, but the main parameter we will use is $\alpha=k_{B} / k_{A}$. It will determine the proportions of acetylene and cyanoacetylene incorporated in the polymer, and the initial reactions will yield the evaluation of the production rates. In this parameterization, the exact process of the polymerization is not crucial. Once the initial products are formed, we assume that they will ultimately form precursors with a mass determined by the incorporated gaseous molecules. Whether other species are incorporated in such polymers is considered here to be second order. Clarke and Ferris (1997) described the incorporation of methane, ethane and carbon monoxide, and it may be possible that HCN also gets incorporated in those chains, but we leave this question open.

\section{Initial reactions:}

The initialization of the polymerization is not a simple question. It could start with the radical $\mathrm{C}_{4} \mathrm{H}_{3}$ or its nitrile equivalent $\mathrm{C}_{4} \mathrm{H}_{2} \mathrm{CN}$ :

Initial scheme (1a):

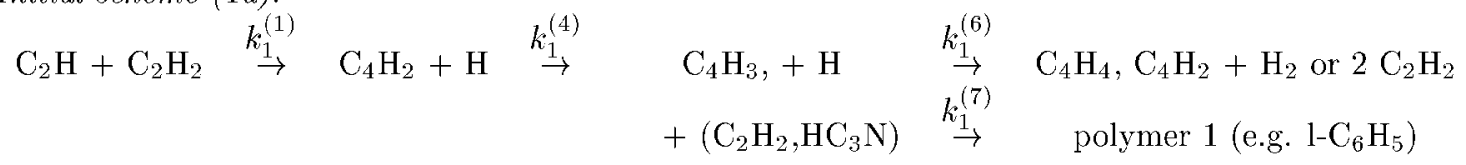


Table II: Proposed parameters

\begin{tabular}{lll}
\hline Polymer & Parameters \\
\hline \multirow{2}{*}{$1 /$ Poly- $\mathrm{C}_{2} \mathrm{H}_{2} / \mathrm{HC}_{3} \mathrm{~N}$} & $k_{1}^{(7,9)}$ & Initial reaction rate coefficients (mainly $\left.\mathrm{C}_{2} \mathrm{H}_{2}+\mathrm{C}_{4} \mathrm{H}_{3}\right)$, in $\mathrm{cm}^{3} \mathrm{~s}^{-1}$ \\
& $\alpha$ & Ratio between $\mathrm{HC}_{3} \mathrm{~N}$ and $\mathrm{C}_{2} \mathrm{H}_{2}$ addition rates \\
& $N_{1}$ & Mean number of molecules in a precursor macromolecule \\
$2 / \mathrm{PAHs}$ & $k_{2}^{(1,2)}$ & Initial reaction rate coefficients $\left(\mathrm{C}_{2} \mathrm{H}_{2}+\mathrm{A}_{1}^{\prime}\right)$, in $\mathrm{cm}^{3} \mathrm{~s}^{-1}$ \\
& $\beta_{1}$ & Ratio between $\mathrm{HCN}$ and $\mathrm{C}_{2} \mathrm{H}_{2}$ addition rates \\
& $\beta_{2}$ & Ratio between $\mathrm{HC}_{3} \mathrm{~N}$ and $\mathrm{C}_{2} \mathrm{H}_{2}$ addition rates \\
& $N_{2}$ & Mean number of molecules incorporated at the precursor level \\
$3 /$ Poly-nitriles & $k_{3}^{(1)}$ & Initial reaction rate coefficient (HCNH $+\mathrm{HCN})$, in $\mathrm{cm}^{3} \mathrm{~s}^{-1}$ \\
& $\gamma_{j}$ & Ratio between nitriles and $\mathrm{HCN}$ addition rates \\
& $N_{3}$ & Mean number of nitrile molecules in a precursor macromolecule \\
\hline
\end{tabular}

Initial scheme (1b):

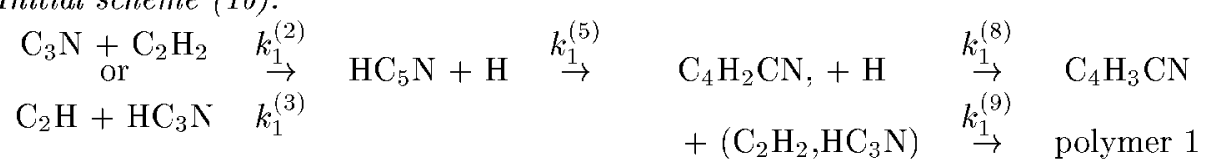

The reactions $\left(\mathrm{C}_{4} \mathrm{H}_{3}, \mathrm{C}_{4} \mathrm{H}_{2} \mathrm{CN}, 1-\mathrm{C}_{6} \mathrm{H}_{5}\right)+\left(\mathrm{C}_{2} \mathrm{H}_{2}, \mathrm{HC}_{3} \mathrm{~N}\right) \rightarrow$ polymer 1 are the first step of the growth scheme.

Possible structures for $\mathrm{C}_{4} \mathrm{H}_{3}$ and $1-\mathrm{C}_{6} \mathrm{H}_{5}$ are shown in Fig. 1. $\mathrm{C}_{3} \mathrm{~N}$ is the nitrile equivalent of $\mathrm{C}_{2} \mathrm{H}: \cdot \mathrm{C} \equiv \mathrm{C}-\mathrm{C} \equiv \mathrm{N}$, produced by the photodissociation of $\mathrm{HC}_{3} \mathrm{~N}$. The reaction rate coefficients (in $\mathrm{cm}^{3} \mathrm{~s}^{-1}$ ) $k_{1}^{(1)}, k_{1}^{(4)}$ and $k_{1}^{(7)}$ have been measured (see references in Table III), but these values may have significant uncertainties due to different conditions between experimental works and Titan's atmosphere, as discussed in photochemical models (e.g. Lebonnois et al., 2001). The rate coefficient $k_{1}^{(6)}$ has been estimated in previous photochemical models, but improved data would be necessary. The other rate coefficients are not known. Rough estimates can be made using an analogy between compounds for $k_{1}^{(2)}, k_{1}^{(3)}, k_{1}^{(5)}, k_{1}^{(8)}$ and $k_{1}^{(9)}$.

The parameter $N_{1}$ (where the subscript refers to the type of polymer) is the mean number of molecules that are incorporated in a chain at the precursor level (by definition, the added mass from gas phase to the aerosol material is negligible after this yield). The relative amount of acetylene vs cyanoacetylene that are added depends on their respective addition rates and their respective number densities. The loss rate of acetylene to the formation of this polymer is

$$
\frac{d n_{\mathrm{C}_{2} \mathrm{II}_{2}}}{d t}=\sum_{j=1}^{J} k_{j, \mathrm{C}_{2} \mathrm{II}_{2}} n_{\mathrm{R}_{j}} n_{\mathrm{C}_{2} \mathrm{II}_{2}}=A_{1, \mathrm{C}_{2} \mathrm{II}_{2}} n_{\mathrm{C}_{2} \mathrm{II}_{2}},
$$

where $\mathrm{R}_{j}(j=1$ to $J)$ are all the different possible radicals that could react with acetylene during this polymer growth, and $k_{j, \mathrm{C}_{2} \mathrm{II}_{2}}$ are the reaction rate coefficients associated with these reactions. The loss rate is therefore related to the acetylene concentration through

$$
A_{1, \mathrm{C}_{2} \mathrm{II}_{2}}=\sum_{j=1}^{J} k_{j, \mathrm{C}_{2} \mathrm{II}_{2}} n_{\mathrm{R}_{\mathrm{j}}}
$$

which we will call the 'addition rate' of acetylene for the formation of polymer 1 . A similar term will be used for the different molecules and the different pathways all along this paper. The parameter $\alpha$ is defined as the ratio between cyanoacetylene and acetylene addition rates. Though this ratio depends in principle of the conditions in the gas under study, it may not vary much with these conditions if the ratio between the rate coefficient of the reaction $\mathrm{R}_{j}+\mathrm{HC}_{3} \mathrm{~N}$ and the rate coefficient of the reaction $\mathrm{R}_{j}+\mathrm{C}_{2} \mathrm{H}_{2}$ does not depend significantly on the radical $\mathrm{R}_{j}$, and on the temperature and pressure of the gas (within a reasonable range). This hypothesis is plausible, but certainly needs further investigation. The fractions of monomers corresponding to each molecule 


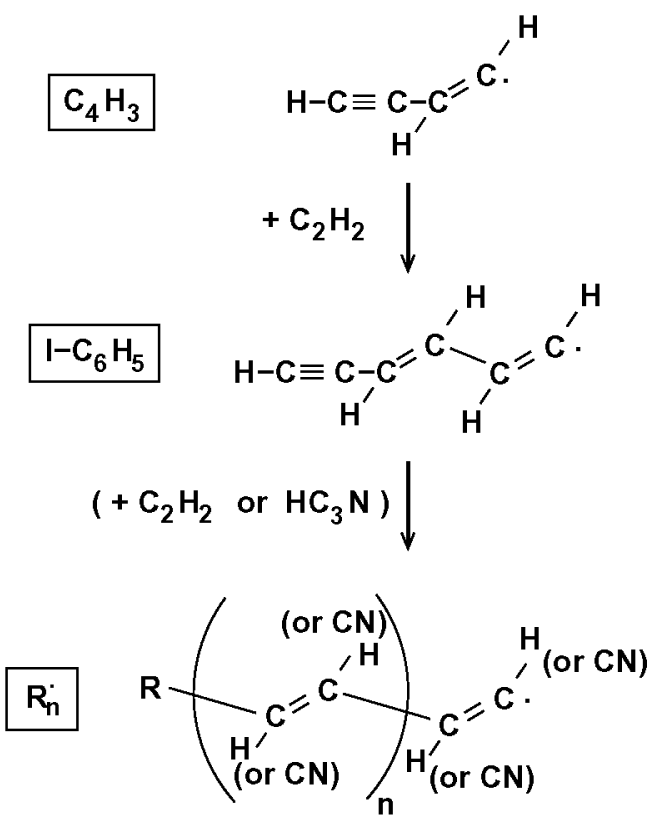

Figure 1: Possible structures for compounds involved in polymer 1 formation.

are:

$$
\begin{aligned}
f_{1, \mathrm{C}_{2} \mathrm{II}_{2}} & =\frac{n_{\mathrm{C}_{2} \mathrm{II}_{2}}}{n_{\mathrm{C}_{2} \mathrm{II}_{2}}+\alpha n_{\mathrm{IIC}_{3} \mathrm{~N}}}, \\
f_{1, \mathrm{IIC}_{3} \mathrm{~N}} & =\frac{\alpha n_{\mathrm{IIC}_{3} \mathrm{~N}}}{n_{\mathrm{C}_{2} \mathrm{II}_{2}}+\alpha n_{\mathrm{IIC}_{3} \mathrm{~N}}},
\end{aligned}
$$

where $n_{i}$ is the number density of the species $i$. The elemental ratios $\mathrm{C} / \mathrm{N}$ and $\mathrm{C} / \mathrm{H}$ can then be calculated. Using these fractions, we evaluate the mean numbers of $\mathrm{C}, \mathrm{H}$ and $\mathrm{N}$ atoms in the resulting polymer chain:

$$
\begin{aligned}
(\mathrm{C} / \mathrm{N})_{1} & =\frac{2 f_{1, \mathrm{C}_{2} \mathrm{II}_{2}}+3 f_{1, \mathrm{IIC}_{3} \mathrm{~N}}}{f_{1, \mathrm{IIC}_{3} \mathrm{~N}}}, \\
(\mathrm{C} / \mathrm{H})_{1} & =\frac{2 f_{1, \mathrm{C}_{2} \mathrm{II}_{2}}+3 f_{1, \mathrm{IIC}_{3} \mathrm{~N}}}{2 f_{1, \mathrm{C}_{2} \mathrm{II}_{2}}+f_{1, \mathrm{IIC}_{3} \mathrm{~N}}} .
\end{aligned}
$$

The production rate of the polymers, $p_{1}$ (in $\mathrm{cm}^{-3} \mathrm{~s}^{-1}$ ) can be evaluated as a function of the composition (concentrations of acetylene, cyanoacetylene and other constituents included in the initialisation scheme) and of the reaction rates of the initial reactions:

$$
p_{1}=n_{\mathrm{C}_{4} \mathrm{II}}\left(k_{1}^{(7 a)} n_{\mathrm{C}_{2} \mathrm{II}_{2}}+k_{1}^{(7 b)} n_{\mathrm{IIC}_{3} \mathrm{~N}}\right)+n_{\mathrm{C}_{4} \mathrm{II}_{2} \mathrm{CN}}\left(k_{1}^{(9 a)} n_{\mathrm{C}_{2} \mathrm{II}_{2}}+k_{1}^{(9 b)} n_{\mathrm{IIC}_{3} \mathrm{~N}}\right) .
$$

Then the mass production rate, $P_{1}$ (in $\mathrm{g} \mathrm{cm}^{-3} \mathrm{~s}^{-1}$ ) is:

$$
P_{1}=m_{1} \times p_{1},
$$

where $m_{1}$ is the mean molecular mass of the polymer:

$$
m_{1}=N_{1} \times\left(f_{1, \mathrm{C}_{2} \mathrm{II}_{2}} m_{\mathrm{C}_{2} \mathrm{II}_{2}}+f_{1, \mathrm{IIC}_{3} \mathrm{~N}} m_{\mathrm{IIC}_{3} \mathrm{~N}}\right) .
$$

The loss rate of acetylene and cyanoacetylene to the polymers are also calculated:

$$
\left(\frac{d n_{\mathrm{C}_{2} \mathrm{II}_{2}}}{d t}\right)_{1}=N_{1} \times f_{1, \mathrm{C}_{2} \mathrm{II}_{2}} \times p_{1},
$$




$$
\left(\frac{d n_{\mathrm{IIC}_{3} \mathrm{~N}}}{d t}\right)_{1}=N_{1} \times f_{1, \mathrm{IIC} \mathrm{C}_{3} \mathrm{~N}} \times p_{1} .
$$

It should be noted that Eq. 1 and Eq. 10 are two different expressions of the same variable: Eq. 1 is detailed from all the different reactions incorporating acetylene in the polymers, while Eq. 10 is obtained because $\left(N_{1} f_{1, \mathrm{C}_{2} \mathrm{II}_{2}}\right)$ molecules of acetylene are statistically incorporated in each chain, and the initial production rate of the chains is $p_{1}$.

\section{$3.2 \quad$ PAH growth (polymer 2)}

If we consider a polymerization including aromatic compounds, the same formalism can be used. Polymerization can start through addition of acetylene on phenyl (noted $\mathrm{A}_{1}^{\prime}$ ), followed by another acetylene addition leading to $\mathrm{A}_{2}, \mathrm{C}_{10} \mathrm{H}_{8}$ (Wang and Frenklach, 1994; Wong et al., 2000; Bauschlicher and Ricca, 2000). Addition would then continue and build up PAHs. The initial reaction considered in this pathway is:

$$
\mathrm{A}_{1}^{\prime}+\mathrm{C}_{2} \mathrm{H}_{2} \stackrel{k_{2}^{(1,2)}}{\rightarrow} \text { PAHs. }
$$

$\mathrm{HCN}$ or $\mathrm{HC}_{3} \mathrm{~N}$ could also be added to form heterocycles (Ricca et al., 2001). The parameters we will use are $\beta_{1}$ and $\beta_{2}$, where $\beta_{1}$ (resp. $\beta_{2}$ ) is the ratio between $\mathrm{HCN}$ (resp. $\mathrm{HC}_{3} \mathrm{~N}$ ) and $\mathrm{C}_{2} \mathrm{H}_{2}$ addition rates. In the polymer 1 , we use only two different possible monomers. Here, we have three different molecules that can be added to the growing macromolecule, and therefore two parameters $\left(\beta_{1}, \beta_{2}\right)$ instead of one $(\alpha)$. Using the same formalism, the fractions of monomers included in the $\mathrm{PAH}$ corresponding to each molecule are:

$$
\begin{aligned}
f_{2, \mathrm{C}_{2} \mathrm{II}_{2}} & =\frac{n_{\mathrm{C}_{2} \mathrm{II}}}{n_{\mathrm{C}_{2} \mathrm{II}_{2}}+\beta_{1} n_{\mathrm{IICN}}+\beta_{2} n_{\mathrm{IIC}_{3} \mathrm{~N}}}, \\
f_{2, \mathrm{IICN}} & =\frac{\beta_{1} n_{\mathrm{IICN}}}{n_{\mathrm{C}_{2} \mathrm{II}_{2}}+\beta_{1} n_{\mathrm{IICN}}+\beta_{2} n_{\mathrm{IIC}_{3} \mathrm{~N}}}, \\
f_{2, \mathrm{IIC} C_{3} \mathrm{~N}} & =\frac{\beta_{2} n_{\mathrm{IIC}_{3} \mathrm{~N}}}{n_{\mathrm{C}_{2} \mathrm{II}_{2}}+\beta_{1} n_{\mathrm{IICN}}+\beta_{2} n_{\mathrm{IIC}_{3} \mathrm{~N}}} .
\end{aligned}
$$

The initial reactions determine the production rate $p_{2}$, then given a maximum size of growth $\left(N_{2}\right.$ is the mean number of molecules included in the PAH at precursor level), the mass production rate $P_{2}$ can be calculated:

$$
P_{2}=m_{2} \times p_{2},
$$

with

$$
m_{2}=N_{2} \times\left(f_{2, \mathrm{C}_{2} \mathrm{II}_{2}} m_{\mathrm{C}_{2} \mathrm{II}_{2}}+f_{2, \mathrm{IICN}} m_{\mathrm{IICN}}+f_{2, \mathrm{IIC}_{3} \mathrm{~N}} m_{\mathrm{IIC}_{3} \mathrm{~N}}\right) .
$$

$\mathrm{C} / \mathrm{H}$ is slightly over 1 , depending on the size of the $\mathrm{PAH}$, and $\mathrm{C} / \mathrm{N}$ is

$$
(\mathrm{C} / \mathrm{N})_{2}=\frac{2 f_{2, \mathrm{C}_{2} \mathrm{II}_{2}}+3 f_{2, \mathrm{IIC}_{3} \mathrm{~N}}+f_{2, \mathrm{IICN}}}{f_{2, \mathrm{IIC}_{3} \mathrm{~N}}+f_{2, \mathrm{IICN}}}
$$

The loss rates of acetylene, hydrogen cyanide and cyanoacetylene to this polymer are:

$$
\begin{aligned}
& \left(\frac{d n_{\mathrm{C}_{2} \mathrm{II}_{2}}}{d t}\right)_{2}=N_{2} \times f_{2, \mathrm{C}_{2} \mathrm{II}_{2}} \times p_{2}, \\
& \left(\frac{d n_{\mathrm{IICN}}}{d t}\right)_{2}=N_{2} \times f_{2, \mathrm{IICN}} \times p_{2}, \\
& \left(\frac{d n_{\mathrm{IIC}_{3} \mathrm{~N}}}{d t}\right)_{2}=N_{2} \times f_{2, \mathrm{IIC}_{3} \mathrm{~N}} \times p_{2} .
\end{aligned}
$$




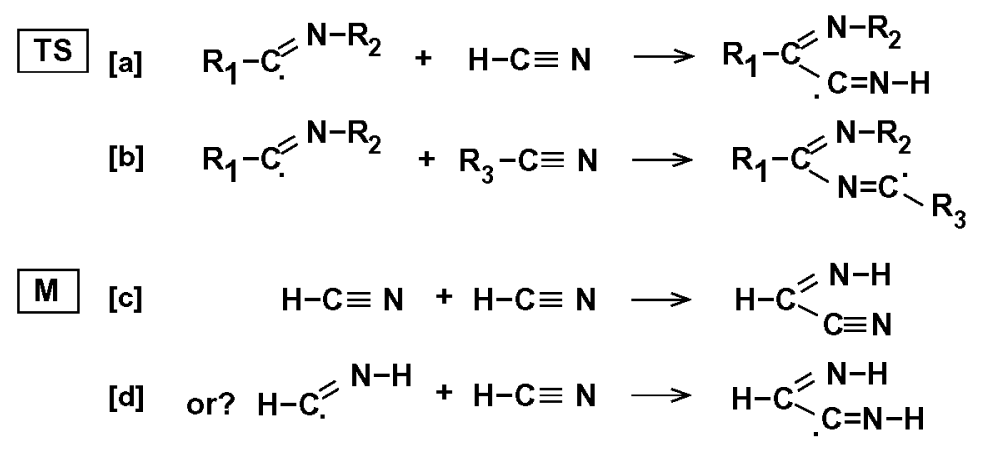

Initial reactions proposed

[e]

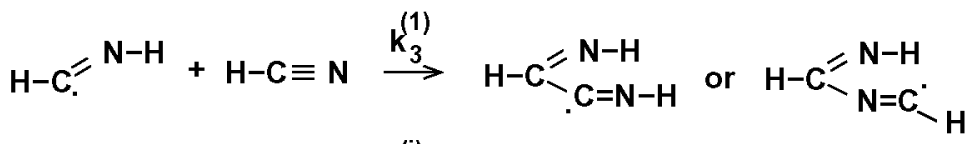

[f]

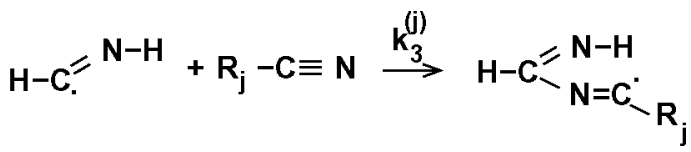

Figure 2: Possible polymerization of nitriles (TS = Thompson and Sagan, 1989; M = Matthews, 1992).

\subsection{HCN and nitrile polymer (polymer 3 )}

The polymerization of HCN has been studied previously (Thompson and Sagan, 1989; Matthews, 1992; Minard et al., 1998). Despite the differences in the proposed structures, it seems possible to reconcile them, so we will explore this possibility. Fig. 2 presents the different reactions that are discussed here. Thompson and Sagan (1989) describe a formation scenario initiated by the reaction of $\mathrm{HCNH}$ radical on a nitrile group. The polymer grows through subsequent N-terminus and C-radical interactions (reaction [b]). In Matthews (1992), scenarios for HCN polymerization proceed mainly by the way of a HCN dimer (reaction $[c]$ ). Following the discussion of Thompson and Sagan, it could be possible to reconcile both schemes if the first HCN dimer were formed by reaction [d], involving $\mathrm{HCNH}$ radical. This hypothesis remains to be addressed in more detail. The exact structure of HCN polymers remains difficult to assess, but based on these studies, we will make the assumption that polymerization starts with the reactions between the $\mathrm{HCNH}$ radical and nitriles (reactions $[\mathrm{e}]$ and [f]). In Titan's atmosphere, the observed nitriles are $\mathrm{HCN}$, then $\mathrm{HC}_{3} \mathrm{~N}$, $\mathrm{C}_{2} \mathrm{~N}_{2}$, and $\mathrm{CH}_{3} \mathrm{CN}$. We add in this study $\mathrm{C}_{2} \mathrm{H}_{3} \mathrm{CN}$, which is predicted as a significant nitrile by our photochemical model of Titan's atmosphere (see Section 4), and which has been detected as a significant nitrile in laboratory experiments (Coll et al., 1999). $N_{3}$ is the mean number of nitrile molecules in the precursors. Once again, the exact structure of the polymer is not crucial. The important factors are the initial reactions chosen, and the relative reactivity of the different nitriles. For each nitrile $\mathrm{R}_{j} \mathrm{CN}\left(\mathrm{R}_{j}\right.$ is $\mathrm{C}_{2} \mathrm{H}, \mathrm{CN}, \mathrm{CH}_{3}$ or $\left.\mathrm{C}_{2} \mathrm{H}_{3}\right)$, we define $\gamma_{j}$ as the ratio of the addition rate of $\mathrm{R}_{j} \mathrm{CN}$ to the addition rate of $\mathrm{HCN}$.

The production rate of polymer $3, p_{3}\left(\mathrm{~cm}^{-3} \mathrm{~s}^{-1}\right)$, can be evaluated as a function of the reaction rate coefficients of the inital reactions and the composition. The different proportions of each nitrile in the polymer are linked to the relative abundance of each nitrile, and its relative reactivity:

$$
f_{3, \mathrm{IICN}}=\frac{n_{\mathrm{IICN}}}{n_{\mathrm{IICN}}+\sum_{j} \gamma_{j} n_{\mathrm{R}_{\mathrm{j}} \mathrm{CN}}},
$$




$$
f_{3, \mathrm{R}_{j} \mathrm{CN}}=\frac{\gamma_{j} n_{\mathrm{R}_{\mathrm{j}} \mathrm{CN}}}{n_{\mathrm{IICN}}+\sum_{j} \gamma_{j} n_{\mathrm{R}_{\mathrm{j}} \mathrm{CN}}} .
$$

The mass production rate $P_{3}\left(\mathrm{~g} \mathrm{~cm}^{-3} \mathrm{~s}^{-1}\right)$ is then:

$$
P_{3}=m_{3} \times p_{3},
$$

with

$$
m_{3}=N_{3} \times\left(f_{3, \mathrm{IICN}} m_{\mathrm{IICN}}+\sum_{j} f_{3, \mathrm{R}_{\mathrm{j}} \mathrm{CN}} m_{\mathrm{R}_{\mathrm{j}} \mathrm{CN}}\right) .
$$

The $\mathrm{C} / \mathrm{N}$ and $\mathrm{C} / \mathrm{H}$ ratios can be calculated, as well as the loss rate of the nitriles to the polymer:

$$
\begin{aligned}
(\mathrm{C} / \mathrm{N})_{3} & =\frac{f_{3, \mathrm{IICN}}+\sum_{j} a_{j}^{\mathrm{C}} f_{3, \mathrm{R}_{\mathrm{j}} \mathrm{CN}}}{f_{3, \mathrm{IICN}}+\sum_{j} a_{j}^{\mathrm{N}} f_{3, \mathrm{R}_{\mathrm{j}} \mathrm{CN}}}, \\
(\mathrm{C} / \mathrm{H})_{3} & =\frac{f_{3, \mathrm{IICN}}+\sum_{j} a_{j}^{\mathrm{C}} f_{3, \mathrm{R}_{\mathrm{j}} \mathrm{CN}}}{f_{3, \mathrm{IICN}}+\sum_{j} a_{j}^{\mathrm{II}} f_{3, \mathrm{R}_{\mathrm{j}} \mathrm{CN}}},
\end{aligned}
$$

where $a_{j}^{\mathrm{C}}, a_{j}^{\mathrm{N}}$, and $a_{j}^{\mathrm{II}}$ are the numbers of $\mathrm{C}, \mathrm{N}$ and $\mathrm{H}$ atoms (respectively) in the $\mathrm{R}_{j} \mathrm{CN}$ molecule, and

$$
\left(\frac{d n_{\mathrm{R}_{\mathrm{j}} \mathrm{CN}}}{d t}\right)_{3}=N_{3} \times f_{3, \mathrm{R}_{\mathrm{j}} \mathrm{CN}} \times p_{3} .
$$

\subsection{Mixing the different polymers}

The precursor level is defined as the yield where chemical growth through addition of mass from the gas phase becomes negligible. Chemical activity is still present (e.g. aging of the polymers, see Dimitrov and Bar-Nun, 2002), but the particles evolve at approximately constant mass, without absorbing any more gas molecules. This statement does not concern possible condensation of gas phase molecules on aerosol particles in the low stratosphere and troposphere (typically between 40 and $150 \mathrm{~km}$ altitude), which is a problem beyond the scope of this paper.

The total mass production rate of the haze is the sum of the different pathways, and the $\mathrm{C} / \mathrm{N}$ and $\mathrm{C} / \mathrm{H}$ mean ratios can be calculated:

$$
\begin{aligned}
& \mathrm{C} / \mathrm{N}=\frac{N_{1} p_{1}\left(2 f_{1, \mathrm{C}_{2} \mathrm{H}_{2}}+3 f_{1, \mathrm{HC}} \mathrm{N}\right)+N_{2} p_{2}\left(2 f_{2, \mathrm{C}_{2} \mathrm{H}_{2}}+3 f_{2, \mathrm{HC}} \mathrm{N}+f_{2, \mathrm{HCN}}\right)+N_{3} p_{3}\left(f_{3, \mathrm{HCN}}+\sum_{j} a_{j}^{\mathrm{C}} f_{3, \mathrm{R}_{\mathrm{j}} \mathrm{CN}}\right)}{N_{1} p_{1} f_{1, \mathrm{HC}_{3} \mathrm{~N}}+N_{2} p_{2}\left(f_{2, \mathrm{HC}_{3} \mathrm{~N}}+f_{2, \mathrm{HCN}}\right)+N_{3} p_{3}\left(f_{3, \mathrm{HCN}}+\sum_{j} a_{j}^{\mathrm{N}} f_{3, \mathrm{R}_{\mathrm{j}} \mathrm{CN}}\right)}, \\
& \mathrm{C} / \mathrm{H}=\frac{N_{1} p_{1}\left(2 f_{1, \mathrm{C}_{2} \mathrm{H}_{2}}+3 f_{1, \mathrm{HC}_{3} \mathrm{~N}}\right)+N_{2} p_{2}\left(2 f_{2, \mathrm{C}_{2} \mathrm{H}_{2}}+3 f_{2, \mathrm{HC}_{3} \mathrm{~N}}+f_{2, \mathrm{HCN}}\right)+N_{3} p_{3}\left(f_{3, \mathrm{HCN}}+\sum_{j} a_{j}^{\mathrm{C}} f_{3, \mathrm{R}_{\mathrm{j}} \mathrm{CN}}\right)}{N_{1} p_{1}\left(2 f_{1, \mathrm{C}_{2} \mathrm{H}_{2}}+f_{1, \mathrm{HC}_{3} \mathrm{~N}}\right)+N_{2} p_{2}\left(2 f_{2, \mathrm{C}_{2} \mathrm{H}_{2}}+f_{2, \mathrm{HC}_{3} \mathrm{~N}}+f_{2, \mathrm{HCN}}\right)+N_{3} p_{3}\left(f_{3, \mathrm{HCN}}+\sum_{j} a_{j}^{\mathrm{H}} f_{3, \mathrm{R}_{j} \mathrm{CN}}\right)} .
\end{aligned}
$$

\subsection{Discussion of parameters}

Table II summarizes the parameters chosen for all polymers. The rate coefficients (measured or estimated) for the initial reactions of each scheme are given in Table III. These reaction rate coefficients have a significant uncertainty. The rate coefficients of $\mathrm{HCNH}$ on $\mathrm{HCN}\left(k_{3}^{(1)}\right)$ is not known. As a first assumption, we will estimate its value from the reaction between $\mathrm{C}_{2} \mathrm{H}_{3}$ and $\mathrm{HCN}$.

\section{Ratios between addition rates}

From a mixture of 250 torr of acetylene and 25 torr of cyanoacetylene, Clarke and Ferris (1997) measured a $\mathrm{C} / \mathrm{N}$ ratio of 6.36 , and a $\mathrm{H} / \mathrm{N}$ ratio of 3.86 . The polymer they report is our first pathway. Using Eq. 5 and Eq. 6 , and a $\mathrm{C}_{2} \mathrm{H}_{2} / \mathrm{HC}_{3} \mathrm{~N}$ concentration ratio equal to 10 , the $\mathrm{C} / \mathrm{N}$ and $\mathrm{C} / \mathrm{H}$ ratios can be fairly well reproduced for $\alpha=6(\mathrm{C} / \mathrm{N}=6.33$ and $\mathrm{H} / \mathrm{N}=4.33)$. This is consistent with laboratory studies showing cyanoacetylene to be two to five times more reactive than acetylene toward polymer formation (Clarke and Ferris, 1995, 1997).

The studies by Ricca et al. (2001) can help constrain $\beta_{1}$ and $\beta_{2}$. The addition step for HCN or $\mathrm{HC}_{3} \mathrm{~N}$ in the process of ring formation shows a barrier very similar to the $\mathrm{C}_{2} \mathrm{H}_{2}$ addition step. The nitrogen atom will then induce a higher barrier in the ring closure process, but this will not 
Table III: Useful reaction rates

\begin{tabular}{|c|c|c|}
\hline Reaction & Reaction rate coefficients $\left(\mathrm{cm}^{3} \mathrm{~s}-1\right)$ & References \\
\hline $\mathrm{C}_{2} \mathrm{H}_{2}+\mathrm{C}_{2} \mathrm{H} \rightarrow \mathrm{C}_{4} \mathrm{H}_{2}+\mathrm{H}$ & $k_{1}^{(1)}=8.6 \times 10^{-16} T^{1.8} e^{474 / T}$ & Opansky and Leone, 1996a \\
\hline $\mathrm{C}_{2} \mathrm{H}_{2}+\mathrm{C}_{3} \mathrm{~N} \rightarrow \mathrm{HC}_{5} \mathrm{~N}+\mathrm{H}$ & $k_{1}^{(2)}=8.6 \times 10^{-16} T^{1.8} e^{474 / T}$ & Estimated from $k_{1}^{(1)}$ (a) \\
\hline $\mathrm{HC}_{3} \mathrm{~N}+\mathrm{C}_{2} \mathrm{H} \rightarrow \mathrm{HC}_{5} \mathrm{~N}+\mathrm{H}$ & $k_{1}^{(3)}=8.6 \times 10^{-16} T^{1.8} e^{474 / T}$ & Estimated from $k_{1}^{(1)}$ (a) \\
\hline $\mathrm{C}_{4} \mathrm{H}_{2}+\mathrm{H}+\mathrm{M} \rightarrow \mathrm{C}_{4} \mathrm{H}_{3}+\mathrm{M}$ & $\begin{array}{l}k_{1}^{(4)}: k_{\infty}=1.39 \times 10^{-10} e^{-1184 / T} \\
k_{0}=1 \times 10^{-28}(\mathrm{c})\end{array}$ & $\begin{array}{l}\text { Nava et al., } 1986 \\
\text { Yung et al., } 1984\end{array}$ \\
\hline $\mathrm{HC}_{5} \mathrm{~N}+\mathrm{H} \rightarrow \mathrm{C}_{4} \mathrm{H}_{2} \mathrm{CN}$ & $\begin{array}{l}k_{1}^{(5)}: k_{\infty}=1.39 \times 10^{-10} e^{-1184 / T} ? \\
k_{0}=1 \times 10^{-28} ?(\mathrm{c})\end{array}$ & Estimated from $k_{1}^{(4)}$ (a) \\
\hline $\mathrm{C}_{4} \mathrm{H}_{3}+\mathrm{H} \rightarrow \mathrm{C}_{4} \mathrm{H}_{4}$ & $k_{1}^{(6 a)}=8.56 \times 10^{-10} e^{-405 / T}$ & Toublanc et al., 1995 \\
\hline $\mathrm{C}_{4} \mathrm{H}_{3}+\mathrm{H} \rightarrow \mathrm{C}_{4} \mathrm{H}_{2}+\mathrm{H}_{2}$ & $k_{1}^{(66)}=1.2 \times 10^{-11}$ & Yung et al., 1984 \\
\hline $\mathrm{C}_{4} \mathrm{H}_{3}+\mathrm{H} \rightarrow 2 \mathrm{C}_{2} \mathrm{H}_{2}$ & $k_{1}^{(6 c)}=3.3 \times 10^{-12}$ & Yung et al., 1984 \\
\hline $\mathrm{C}_{4} \mathrm{H}_{3}+\mathrm{C}_{2} \mathrm{H}_{2} \rightarrow \mathrm{l}-\mathrm{C}_{6} \mathrm{H}_{5}$ & $k_{1}^{(7 a)}=2 \times 10^{-16}$ & Wang and Frenklach, 1994 \\
\hline $\mathrm{C}_{4} \mathrm{H}_{3}+\mathrm{HC}_{3} \mathrm{~N}(\rightarrow$ polymer 1$)$ & $k_{1}^{(76)}=1.2 \times 10^{-15}$ & Estimated from $\alpha \times k_{1}^{(7)}$ \\
\hline $\mathrm{C}_{4} \mathrm{H}_{2} \mathrm{CN}+\mathrm{H} \rightarrow \mathrm{C}_{4} \mathrm{H}_{3} \mathrm{CN}$ & $k_{1}^{(8)}=8.56 \times 10^{-10} e^{-405 / T} ?$ & Estimated from $k_{1}^{(6 a)}(\mathrm{a})$ \\
\hline $\mathrm{C}_{4} \mathrm{H}_{2} \mathrm{CN}+\mathrm{C}_{2} \mathrm{H}_{2}(\rightarrow$ polymer 1$)$ & $k_{1}^{(9 a)} \sim 2 \times 10^{-16} ?$ & Estimated from $k_{1}^{(7)}$ (a) \\
\hline $\mathrm{C}_{4} \mathrm{H}_{2} \mathrm{CN}+\mathrm{HC}_{3} \mathrm{~N}(\rightarrow$ polymer 1$)$ & $k_{1}^{(96)} \sim 1.2 \times 10^{-15} ?$ & Estimated from $\alpha \times k_{1}^{(7)}$ (a) \\
\hline $1-\mathrm{C}_{6} \mathrm{H}_{5}+\mathrm{C}_{2} \mathrm{H}_{2}(\rightarrow$ polymer 1$)$ & $2 \times 10^{-16} ?$ & Estimated from $k_{1}^{(7)}(\mathrm{b})$ \\
\hline $\mathrm{l}_{-} \mathrm{C}_{6} \mathrm{H}_{5}+\mathrm{HC}_{3} \mathrm{~N}(\rightarrow$ polymer 1$)$ & $1.2 \times 10^{-15} ?$ & Estimated from $\alpha \times k_{1}^{(7)}(\mathrm{b})$ \\
\hline $\mathrm{A}_{1}^{\prime}+\mathrm{C}_{2} \mathrm{H}_{2} \rightarrow \mathrm{A}_{1} \mathrm{C}_{2} \mathrm{H}+\mathrm{H}$ & $k_{2}^{(1)}=6.6 \times 10^{-17} T^{1.56} e^{-1913 / T}$ & Wang and Frenklach, 1994 \\
\hline $\mathrm{A}_{1}^{\prime}+\mathrm{C}_{2} \mathrm{H}_{2} \rightarrow \mathrm{A}_{1} \mathrm{C}_{2} \mathrm{H}_{2}$ & $k_{2}^{(2)}=9.8 \times 10^{-13} T^{0.21} e^{-2517 / T}$ & Wang and Frenklach, 1994 \\
\hline $\mathrm{HCNH}+\mathrm{HCN}(\rightarrow$ polymer 3$)$ & $k_{3}^{(1)}=1 \times 10^{-12} e^{-900 / T} ?$ & $\begin{array}{l}\text { Estimated from } \mathrm{C}_{2} \mathrm{H}_{3}+\mathrm{HCN} \text {, } \\
\text { Monks et al., } 1993\end{array}$ \\
\hline HCNH + nitriles $(\rightarrow$ polymer 3 ) & $k_{3}^{(j)}=\gamma_{j} \times k_{3}^{(1)}$ & parameters \\
\hline
\end{tabular}

(a) If we neglect the pathway through $\mathrm{C}_{4} \mathrm{H}_{2} \mathrm{CN}$ against the one through $\mathrm{C}_{4} \mathrm{H}_{3}$ (because of their relative abundance), then these values are secondary.

(b) We consider that once $1-\mathrm{C}_{6} \mathrm{H}_{5}$ is reached, all molecules will eventually yield a polymer. In this approximation, these rates are of secondary importance.

(c) $k_{0}$ values are in $\mathrm{cm}^{6} \mathrm{~s}^{-1}$.

have consequences on the $f_{2}$ factors. It may slow the growth process, but it will eventually lead to precursor formation. As a rough hypothesis, we consider the assumption $\beta_{1} \sim \beta_{2} \sim 1$.

For polymer 3 , in the absence of any data, we will make the crude assumption that all nitriles have the same addition rate in the polymer. The parameters $\gamma_{j}$, ratios of the addition rate of a nitrile $\mathrm{R}_{j} \mathrm{CN}$ to the addition rate of $\mathrm{HCN}$ are therefore taken equal to 1 for all nitriles.

\section{Length of the polymers}

The mean length of the polymers (related to the $N_{i}$ parameters) may be controlled by the details of the chain reactions. To estimate the extent of the molecules' incorporation at the precursor level (i.e. $N_{i}$ ), we use here a different approach. The usual density for aerosol particles is around $1 \mathrm{~g} \mathrm{~cm}^{-3}$ (Toon et al., 1992; Rannou et al., 1995). The size of the smallest particles used in these microphysical models for aerosol production is around $13 \AA$. The mass of these precursors is therefore of the order of $9 \times 10^{-21} \mathrm{~g}$, which corresponds to $\sim 200$ molecules of acetylene or hydrogen cyanide, or $\sim 400$ atoms of carbon and/or nitrogen. The precursor level that is used in our model is taken before or around that size. Therefore, we will assume that $N_{i}$ are all of the order of 10 to 100 gas molecules (and that $N_{1} \sim N_{2} \sim N_{3}$ ). Our chosen value is 20, which means that the precursors contains $\sim 10$ polymer macromolecules, which have incorporated each a mean value of 20 gas phase molecules before the chemical growth from the gas phase becomes negligible. This is consistent with the estimation given in Dimitrov and Bar-Nun (2002), stating that a particle of radius (3-8) ^ may already consist of (12-20) macromolecules. 
Table IV: Chosen parameter values

\begin{tabular}{lc}
\hline Parameter & Value \\
\hline$\alpha$ & 6 \\
$\beta_{1}, \beta_{2}, \gamma_{j}$ & 1 \\
$N_{1}, N_{2}, N_{3}$ & 20 \\
\hline
\end{tabular}

\section{Application to the atmosphere of Titan}

\subsection{Model}

In this study, we use a 1-dimensional photochemical model, updated from Toublanc et al. (1995) (Lebonnois and Toublanc, 1999; Lebonnois et al., 2001). The eddy diffusion coefficient profile has been modified in order that the vertical profiles of the atmospheric components obtained from this model are similar to those obtained with our recent 2-dimensional model (Lebonnois et al., 2001). The vertical composition of the atmosphere is sensitive to the diffusion coefficient, but few constraints are available: the analysis of Voyager 1/IRIS observations by Coustenis et al. $(1989,1995)$ constrain the composition in the $[100-130] \mathrm{km}$ region (low stratosphere), and a recent reanalysis of Voyager 1 /UVS data by Vervack (1997) proposes vertical profiles for some compounds in the [500-800] km region. The 2-dimensional dynamics we introduced in the stratosphere in our model (Lebonnois et al., 2001) have a major impact on these profiles in this region, yielding a more homogeneous stratosphere. The eddy diffusion coefficient profile has been tuned here to reproduce this effect, and to bring most profiles in agreement with Voyager 1 observations (see Fig. 3). We have added to the model the production of aerosol precursors and corresponding loss of gas phase components, using the parameterization described previously. The chosen set of parameters is given in Table IV.

Our goals here are to get a first idea of the impact of this parameterization on the photochemical model, to evaluate the possible production rate (its vertical profile and its column integrated value) of precursors in these conditions, and the composition we obtain for Titan's aerosol precursors.

\subsection{Results}

Fig. 3

The profiles of components of interest for this study are shown in Fig. 3: hydrocarbon molecules $\left(\mathrm{C}_{2} \mathrm{H}_{2}, \mathrm{C}_{4} \mathrm{H}_{2}\right.$, benzene $\left[\mathrm{A}_{1}\right]$ ), nitriles $\left(\mathrm{HCN}, \mathrm{HC}_{3} \mathrm{~N}, \mathrm{C}_{2} \mathrm{~N}_{2}, \mathrm{CH}_{3} \mathrm{CN}, \mathrm{C}_{2} \mathrm{H}_{3} \mathrm{CN}\right)$, and radicals $\left(\mathrm{C}_{4} \mathrm{H}_{3}\right.$, HCNH, phenyl $\left.\left[A_{1}^{\prime}\right]\right)$. The impact on their profiles of the loss of these molecules to the aerosols is also indicated in this figure. As previously suggested by McKay (1996), this loss appears as a significant sink for the nitriles, but not for the hydrocarbons.

The profiles obtained for the mass production rates of each polymer are shown in Fig. 4 . The maxima are all located between 150 and $200 \mathrm{~km}$ altitude. This is essentially a mirror of the density profiles of the different radicals, the maxima being slightly lowered by the increasing densities of acetylene and hydrogen cyanide. The column integrated values of the mass production rates are indicated in Table V, at two different steps: just after the initial reactions (before addition of any other gas molecules), and at the precursor level.

Polymers 1 and 3 are of similar importance, while the PAHs component (polymer 2) appears negligible by several orders of magnitude, due to the low mole fraction of phenyl (and therefore benzene) in the stratosphere, and to the addition rate of acetylene on phenyl, which is much lower than the other initial reactions at this temperature (in the range $150-200 \mathrm{~K}$ ).

The profiles of the $\mathrm{C} / \mathrm{N}$ ratios are plotted in Fig. 5. This model (through Eq. 28) gives a value of $\mathrm{C} / \mathrm{N}$ in Titan's stratosphere of approximately 4 , which is a mix of polymer 1 with $(\mathrm{C} / \mathrm{N})_{1} \simeq 18$, and polymer 3 with $(\mathrm{C} / \mathrm{N})_{3} \simeq \mathbf{1 . 5}$. The $\mathrm{C} / \mathrm{H}$ ratios are always slightly above 1 .

\subsection{Discussion}

\section{Experiments}


a)

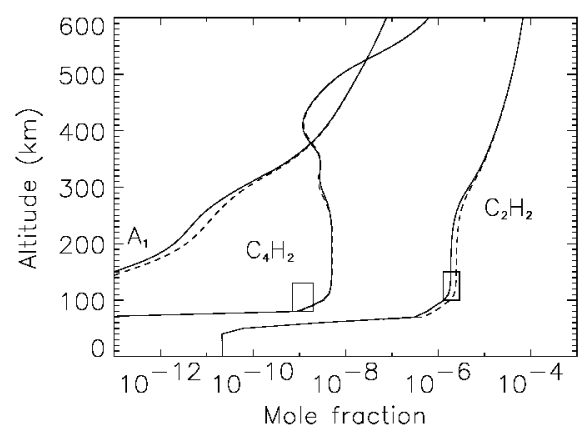

c)

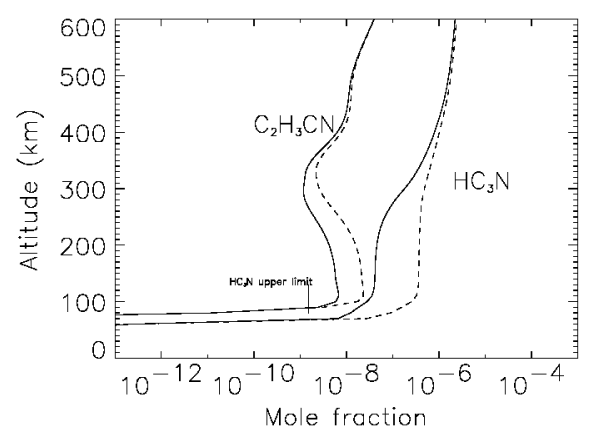

b)

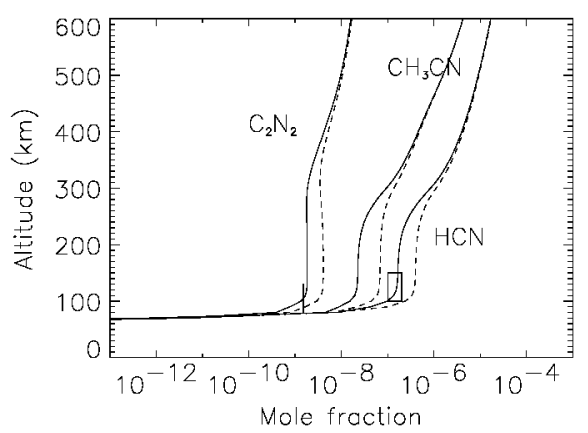

d)

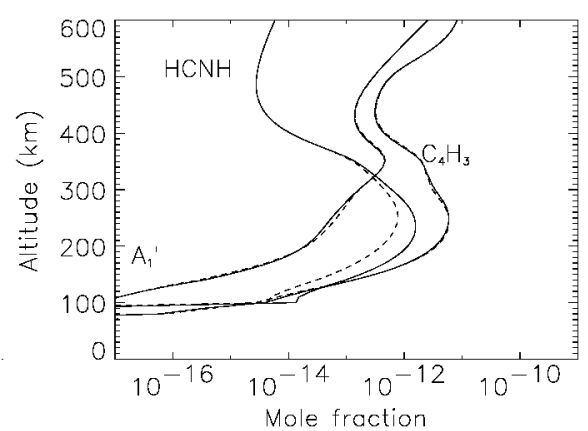

Figure 3: Profiles of some compounds of interest: (a) Hydrocarbons; (b,c) Nitriles; (d) Radicals. Solid lines: with the loss of these molecules to the haze; dashed lines: without this loss. The analysis of Voyager 1/IRIS spectra (Coustenis and Bézard, 1995) is indicated as boxes (or vertical bars for upper limits).

Thompson et al. (1991), McDonald et al. (1994), and Coll et al. (1999) have produced tholins in experiments where gas phase compositions were close to Titan's stratosphere. Though the other experimental conditions (temperature, pressure, energy source) are not a perfect reproduction of Titan's atmospheric conditions, the optical properties of tholins they produced provide good matches to the properties of Titan's haze (Sagan et al., 1992). The $\mathrm{C} / \mathrm{N}$ ratios they measured (Table I) appears to be close to the global ratio we obtain around the maximum of the production. The $\mathrm{C} / \mathrm{H}$ ratios they report are lower than unity, which is different from our value, but this can be understood as a consequence of the hydrogenation of the different $\mathrm{C}-\mathrm{C}$ or $\mathrm{C}-\mathrm{N}$ multiple bounds which can occur during the polymerization process, and that is not taken into account in our parameterization. Another process could also be the addition of methyl groups, due to the high abundance of methane.

In the Coll et al. (1999) experiment, HCN polymers (polymer 3) were reported to be likely present,

Table V: Column integrated production rate at two different steps and the altitude of the maximum production rate $z_{\max }$

\begin{tabular}{|c|c|c|c|}
\hline \multirow[b]{2}{*}{ Polymer 1} & \multicolumn{2}{|c|}{$\begin{array}{c}\text { Initial reactions Precursor level }(\mathcal{P} \\
\left(\mathrm{g} \mathrm{cm}^{-2} \mathrm{~s}^{-1}\right)\end{array}$} & \multirow{2}{*}{$\begin{array}{c}\begin{array}{c}z_{\max } \\
(\mathrm{km})\end{array} \\
150-200\end{array}$} \\
\hline & $2.8 \times 10^{-15}$ & $2.3 \times 10^{-14}$ & \\
\hline Polymer 2 & $3.9 \times 10^{-19}$ & $2.4 \times 10^{-18}$ & $180-220$ \\
\hline Polymer 3 & $2.5 \times 10^{-15}$ & $1.8 \times 10^{-14}$ & $150-200$ \\
\hline Total & $5.3 \times 10^{-15}$ & $4.1 \times 10^{-14}$ & $150-200$ \\
\hline Toon et al. (1992) & & $1.2 \times 10^{-14}$ & $200-300$ \\
\hline Rannou et al. (1995) & - & $2.1 \times 10^{-14}$ & 385 \\
\hline
\end{tabular}




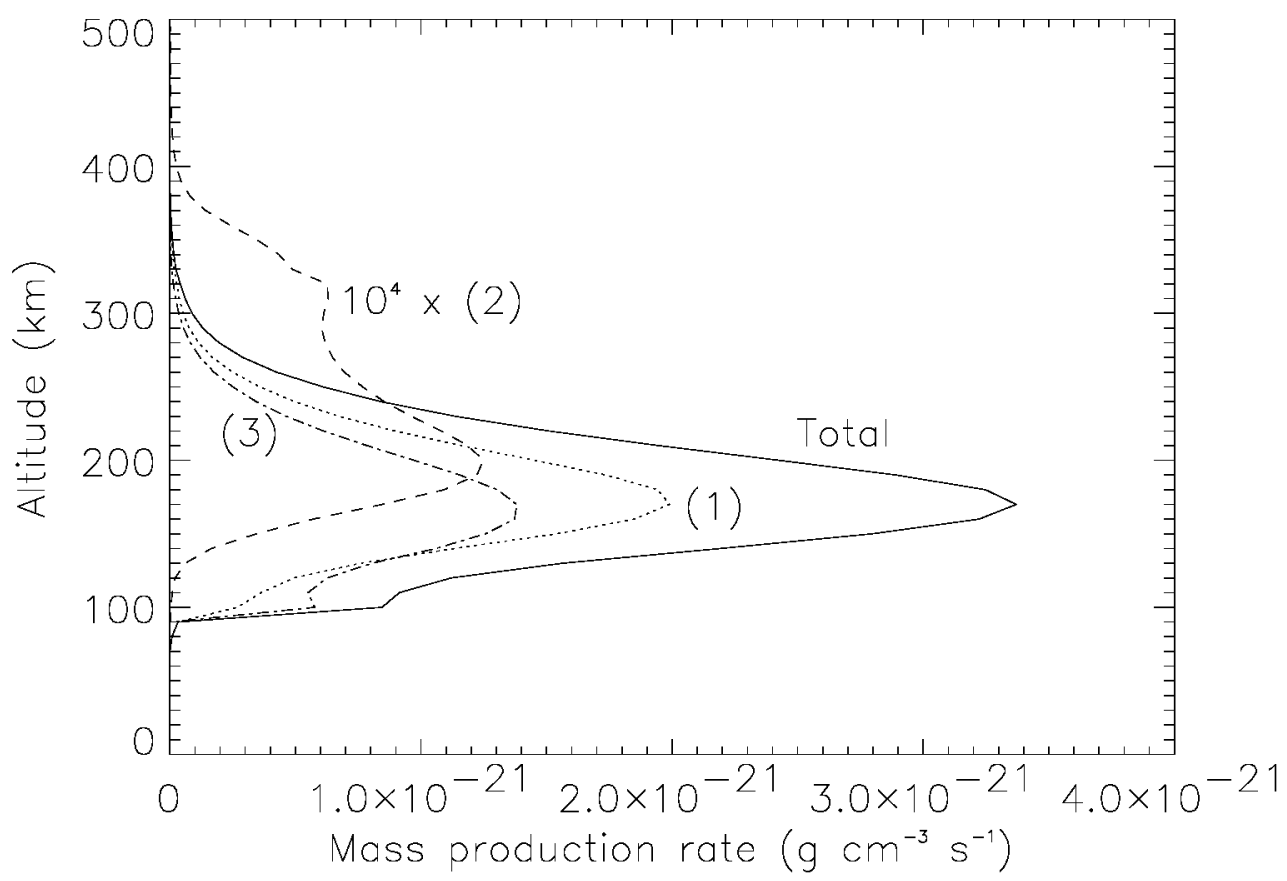

Figure 4: Profiles of the mass production rates for each polymerization pathway.

and the $\mathrm{C} / \mathrm{N}$ ratio is fairly similar to the one we get for our simulations, though slightly lower. For the series of experiments initiated by Khare et al. (1984), the presence of polyaromatics have been reported, though Thompson et al. (1991) do not indicate any production yield for benzene. It is worth noting that these experiments have been conducted at room temperature (300K, compared to approximately $170 \mathrm{~K}$ in Titan's stratosphere, and 100-150K in Coll et al. (1999) experiment). This has a large impact on the addition rate of acetylene on the phenyl radical $\left(k_{2}^{(1+2)}\right.$ varies by more than three orders of magnitude between 150 and 300K), which could yield a much higher production rate of PAHs at room temperature, comparable to the two other kinds of polymers. Another possibility is that we are missing some other pathways to produce benzene (or other ring molecules), like the reaction proposed in Arrington et al. (1998) between 1,3-butadiene and metastable diacetylene.

\section{Microphysical models}

Two different classes of microphysical models for the haze structure and evolution have been proposed to reproduce several sets of observational data (Titan's albedo, polarization of scattered light, high phase angle brightness). The models differ by the shape of the aerosol particles. In one class the particles keep a spherical shape during their growth. In the other the particles form aggregates of small spheres, with a fractal shape. The maxima of production and the values of total mass production rates needed by the Toon et al. (1992) (spherical particles) and Rannou et al. (1995) (fractal particles) models are indicated in Table $\mathrm{V}$, for comparison with our model.

The region of maximum mass production we obtain appears to be lower than expected by both these microphysical models. In our model, the position of this region is controlled by the vertical profiles of the radicals involved in the initial reactions $\left(\mathrm{C}_{4} \mathrm{H}_{3}, \mathrm{HCNH}\right)$. However, dynamical conditions in the stratosphere play an important role in the aerosols' evolution and distribution, and in the compounds' distribution. Winds associated with the general circulation are likely to carry small particles upward and may therefore result in a higher effective altitude of production than predicted here. This has been observed in coupled dynamics and microphysical models (Rannou et al., submitted to Nature).

From methane photodissociation yields, Podolak and Bar-Nun (1979) estimated the production rate of $\mathrm{C}_{2} \mathrm{H}_{2}$ and $\mathrm{C}_{2} \mathrm{H}_{4}$ (which is then mostly photodissociated into acetylene). Comparing this 


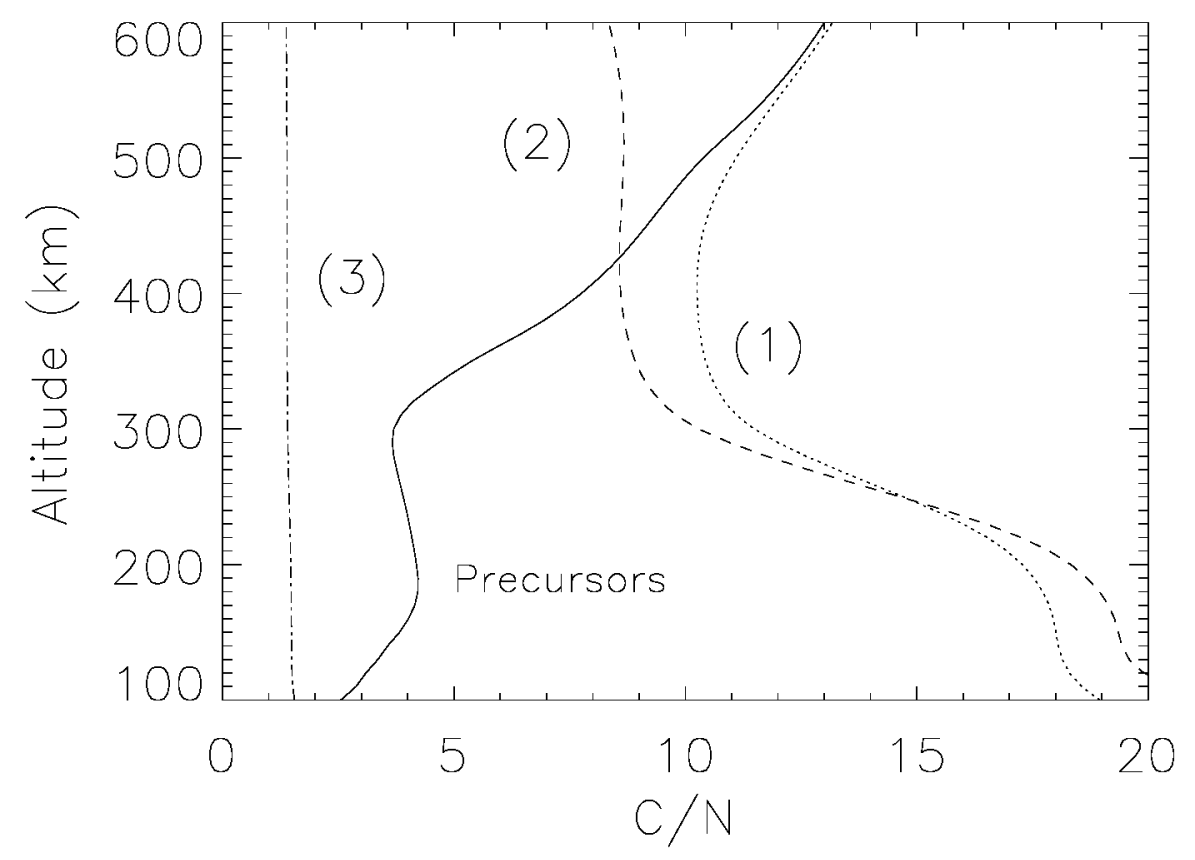

Figure 5: $\mathrm{C} / \mathrm{N}$ ratios for the different pathways, and for the precursors.

value $\left(3 \times 10^{-14} \mathrm{~g} \mathrm{~cm}^{-2} \mathrm{~s}^{-1}\right)$ to our production rate for polymer 1 is not straightforward since this polymer contains $\mathrm{HC}_{3} \mathrm{~N}$, and since the photochemical model takes into account all the other sinks of acetylene and ethylene. But to first order, our value is indeed consistent with those simple photochemical considerations.

The total integrated mass production rate is higher than expected by both microphysical models, but the values we obtain at the precursor level should be taken as upper limits, since some intermediate molecules could be lost through condensation before they reach this level. Also, the influence of 2-dimensional dynamics may affect the calculated production rate, as well as the values expected from the microphysical models.

To evaluate the role of the dynamical conditions in the stratosphere, it will be necessary to test this parameterization in a coupled model, including a general circulation model, a photochemical model and a microphysical model, in order to draw a more complete conclusion.

\section{Variations of parameters}

In order to test the sensitivity of our results against parameters variations, we varied the values of $N_{i}, \alpha, \beta_{1}, \beta_{2}, \gamma_{j}$, and $k_{3}^{(1)}$. First, we looked at the impact of the lengths of the chains at the precursor level $\left(N_{i}\right)$ on the production rates of the three kinds of polymers. Were the composition of the gas phase fixed, the mass production rate $P_{i}$ would be proportional to $N_{i}$ (Eqs. 8 and 9 for pathway 1) in the context of this model. This only means that for a given production rate of the first heavy molecules, the more parent molecules that are incorporated in a polymer, the heavier the macromolecules that constitute precursors, and the higher the total mass production rate of precursors. But increasing $N_{i}$ can affect the vertical profiles of gas phase molecules, if this loss to the haze becomes a dominant sink. Simulations were done with $N_{i}=20,50$ and 80 . The integrated mass production rates $\mathcal{P}_{i}$ as functions of $N_{i}$ are plotted in Fig. 6. $\mathcal{P}_{1}$ and $\mathcal{P}_{2}$ vary significantly with $N_{1}$ and $N_{2}$, respectively, because this sink is not dominant for the hydrocarbons, and therefore $p_{1}$ and $p_{2}$ only slightly vary with $N_{1}$ and $N_{2}$. This is not the case for $\mathcal{P}_{3}$, because this sink is significant for the nitriles. When $N_{3}$ increases, the nitrile mole fraction in the stratosphere decreases, and $\mathcal{P}_{3}$ reaches a limit.

The parameters $\alpha, \beta$ and $\gamma$ may be dependent on the conditions in the atmosphere of Titan (or in the laboratory experiments). Therefore, we modified them alternatively, raising or lowering their 


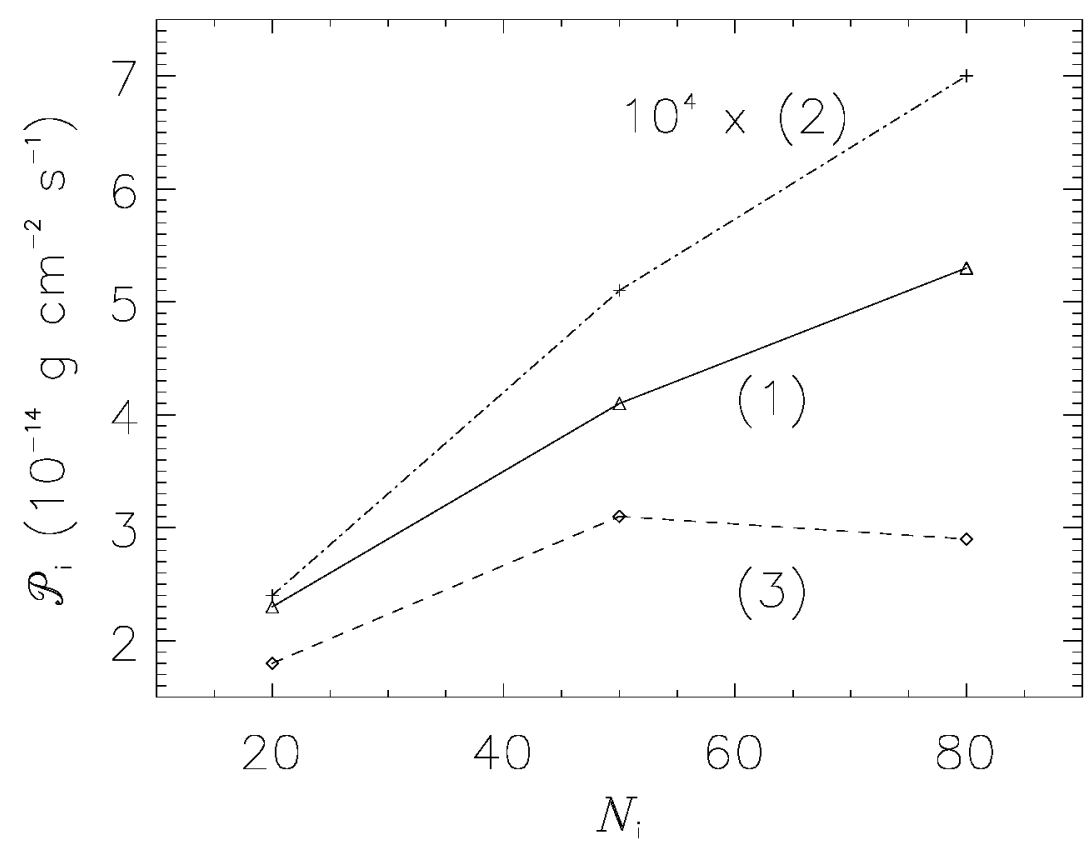

Figure 6: Integrated mass production rate $\left(\mathcal{P}_{i}\right.$, in $\left.\mathrm{g} \mathrm{cm}^{-2} \mathrm{~s}^{-1}\right)$ as a function of the parent molecules incorporated in the polymers at the precursor level $\left(N_{i}\right)$.

values by an order of magnitude. Concerning the first pathway, the value of $\alpha$ has an influence on the loss rate of $\mathrm{HC}_{3} \mathrm{~N}$ to the haze. Variations around $\alpha=6$ does not affect $\mathrm{C}_{2} \mathrm{H}_{2}$ in the gas phase, but has an impact on $\mathrm{HC}_{3} \mathrm{~N}$ stratospheric abundance, since this pathway represents a significant loss for this compound. It also affects the $(\mathrm{C} / \mathrm{N})_{1}$ ratio (from $\sim 10$ to $\sim 150$ ), as well as the mean molecular mass $m_{1}$ (small variations, around $5 \%$ ), but the impact on the global $\mathrm{C} / \mathrm{N}$ ratio and on the total mass production rate is small in the stratosphere (within 10\%). Because polymer 2 is negligible compared to polymer 3 , the values of $\beta_{1}$ and $\beta_{2}$ do not have any influence on the HCN and $\mathrm{HC}_{3} \mathrm{~N}$ vertical profiles. They also have little influence on $m_{2}$ and $P_{2}$ : in the case of $\beta_{1}, \mathrm{C}_{2} \mathrm{H}_{2}$ and HCN have similar molecular mass, and in the case of $\beta_{2}, \mathrm{HC}_{3} \mathrm{~N}$ mole fraction is significantly lower than both other compounds. The effect of $\beta_{1}$ and $\beta_{2}$ variations is only visible in the $(\mathrm{C} / \mathrm{N})_{2}$ ratio, but due to its negligible production rate, this does not influence the global $\mathrm{C} / \mathrm{N}$ ratio. We tested the impact of $\gamma$ variations for $\mathrm{HC}_{3} \mathrm{~N}$ in a similar manner. When $\gamma$ is raised for this nitrile, it increases its proportion in polymer 3. The molecular mass of the polymer changes accordingly (e.g. for $\mathrm{HC}_{3} \mathrm{~N}$, it raises the molecular mass), affecting the mass production rate $P_{3}$. The $(\mathrm{C} / \mathrm{N})_{3}$ is also slightly affected. The destruction rate of this nitrile increases, which affects its vertical profile. The overall variations of the global $\mathrm{C} / \mathrm{N}$ ratio and mass production rate are small, within $30 \%$.

Finally, variations on the value of the reaction rate coefficient between $\mathrm{HCNH}$ and $\mathrm{HCN}\left(k_{3}^{(1)}\right)$ induce correlated variations on $\mathrm{HCNH}$ mole fraction profile (with only small variations on the nitriles' profiles), but the production rate remains largely unchanged. This is consistent with these reactions being the dominant sink of the $\mathrm{HCNH}$ radical in this model.

\section{Conclusions}

Based on experimental data, three pathways have been proposed in order to bridge the gap between the usual photochemical scheme and the microphysical models: polymers of acetylene and cyanoacetylene, polycyclic aromatic hydrocarbons (that could include some nitrogen in the rings), 
and polymers of $\mathrm{HCN}$ and other nitriles. The parameterization proposed here allows us to estimate mass production rates, loss rates of gas phase molecules to the aerosols, and the $\mathrm{C} / \mathrm{N}$ ratio obtained in the precursors for each production channel. A basic set of parameters is used to apply this model to Titan's atmosphere. The following conclusions can then be derived:

1/ We have been able to parameterize the mass production function of aerosol precursors from the photochemistry, given a certain number of assumptions: initial reactions leading to different types of polymers; relative incorporation of different kind of monomers in each polymer structure; gas molecules incorporation occuring until the macromolecules reach a given size (precursor level); no heterogenous nor ion chemistry considered.

$2 /$ Though the comparison of the resulting $\mathrm{C} / \mathrm{N}$ ratio and main products to the experiments are promising, the values determined for the mass production rate and the altitude of the peak production are only marginally in agreement with the values that 1-dimensional microphysical models require.

3/ Variations of the different parameters around their chosen values do not significantly affect the results, except for the length of the polymers at the precursor level.

4/ This approach can help bridge the gap between gas phase molecules and the macromolecules that are building the aerosols in a simple way, without getting into the details of the polymers structures. For this parameterization to be effective, it needs a qualitative understanding of the initial reactions, as well as a quantitative assessment of the different parameters. Efforts should continue in this direction, in particular through more detailed analysis of experimental data. The simultaneous characterization of the tholins (types of bounds, aliphatics vs PAHs, HCN polymers, $\mathrm{C} / \mathrm{N}$ and $\mathrm{C} / \mathrm{H}$ ratios) and measurement of the gas phase composition (mole fractions of as many compounds as possible) are needed to help constrain the production mechanism of the tholins. It would be useful to have such experimental data in different initial conditions, especially with different initial mixtures: apart from the usual $\mathrm{N}_{2} / \mathrm{CH}_{4}$, it could also be $\mathrm{C}_{2} \mathrm{H}_{2} / \mathrm{HCN}(14 / 1)$, for example.

5/ The first results we obtain here should also be tested with a coupled model (dynamics, photochemistry and haze microphysics), especially since dynamics can affect significantly the required production conditions. This will help build a complete model of Titan's atmospheric system, as a powerful tool for the exploitation of Cassini/Huygens data.

\section{Acknowledgement}

This work was performed while S. Lebonnois held a National Research Council Research Associateship Award at NASA Ames Research Center. E.L.O. Bakes thanks NASA's Exobiology Program for her support in this research. The authors thank Kevin Zahnle for a very useful discussion of this paper.

\section{References}

Arrington, C. A., C. Ramos, A. D. Robinson, and T. S. Zwier 1998. Aromatic ring-forming reactions of metastable diacetylene with 1,3-butadiene. J. Phys. Chem. A 102, 3315-3322.

Bar-Nun, A., I. Kleinfeld, and E. Ganor 1988. Shape and optical properties of aerosols formed by photolysis of acetylene, ethylene and hydrogen cyanide. J. Geophys. Res. 93, 8383-8387.

Bauschlicher, C. W., Jr., and A. Ricca 2000. Mechanisms for polycyclic aromatic hydrocarbon (PAH) growth. Chem. Phys. Lett. 326, 283-287.

Clarke, D. W., and J. P. Ferris 1995. Photodissociation of cyanoacetylene: Application to the atmospheric chemistry of Titan. Icarus 115, 119-125.

Clarke, D. W., and J. P. Ferris 1997. Titan haze: Structure and properties of cyanoacetylene and cyanoacetylene-acetylene photopolymers. Icarus 127, 158-172.

Coll, P., D. Coscia, M.-C. Gazeau, E. de Vanssay, J.-C. Guillemin, and F. Raulin 1995. Organic chemistry in Titan's atmosphere: New data from laboratory simulations at low temperature. Adv. Space Res. 16 (2), 93-103.

Coll, P., D. Coscia, S. Smith, M.-C. Gazeau, S. I. Ramirez, G. Cernogora, G. Israël, and F. Raulin 1999. Experimental laboratory simulation of Titan's atmosphere: Aerosols and gas phase. Planet. BS Space Sci. 47, 1331-1340.

Coustenis, A., and B. Bézard 1995. Titan's atmosphere from Voyager infrared observations.IV. Latitudinal variations of temperature and composition. Icarus 115, 126-140. 
Coustenis, A., B. Bézard, and D. Gautier 1989. Titan's atmosphere from Voyager infrared observations.I. The gas composition of Titan's equatorial region. Icarus $\mathbf{8 0}, 54-76$.

Dimitrov, V., and A. Bar-Nun 1997. An Adequate Kinetic Model of the photochemical formation of hydrocarbon aerosols in Titan's atmosphere. Prog. Reaction Kinetics 22, 3-66.

Dimitrov, V., and A. Bar-Nun 1999. A model of energy-dependent agglomeration of hydrocarbon aerosol particles and implications to Titan's aerosol. J. Aerosol Sci. 30, 35-49.

Dimitrov, V., and A. Bar-Nun 2002. Aging of Titan's aerosols. Icarus 156, 530-538.

Khare, B. N., E. Bakes, H. Imanaka, C. P. McKay, D. P. Cruikshank, and E. T. Arakawa 2001. Analysis of the time dependent chemical evolution of Titan haze tholin. Icarus. Submitted.

Khare, B. N., C. Sagan, E. T. Arakawa, F. Suits, T. A. Callcott, and M. W. Williams 1984 . Optical constants of organic tholins produced in a simulated titanian atmosphere: from soft $\mathrm{X}$-rays to microwaves frequencies. Icarus 60, 127-137.

Lara, L. M., E. Lellouch, J. J. López-Moreno, and R. Rodrigo 1996. Vertical distribution of Titan's atmospheric neutral constituents. J. Geophys. Res. 101 (E10), 23,261-23,283.

Lebonnois, S., and D. Toublanc 1999. Actinic fluxes in Titan's atmosphere, from one to three dimensions: Application to high-latitude composition. J. Geophys. Res. 104 (E9), 22,025-22,034.

Lebonnois, S., D. Toublanc, F. Hourdin, and P. Rannou 2001. Seasonal variations in Titan's atmospheric composition. Icarus 152, 384-406.

Matthews, C. N. 1992. Dark matter in the solar system: Hydrogen cyanide polymers. Origins of Life Evol. Biosphere 21, 421-434.

McDonald, G. D., W. R. Thompson, M. Heinrich, B. N. Khare, and C. Sagan 1994. Chemical investigation of Titan and Triton tholins. Icarus 108, 137-145.

McKay, C. P. 1996. Elemental composition, solubility, and optical properties of Titan's organic haze. Planet. \& Space Sci. 44 (8), 741-747.

McKay, C. P., J. B. Pollack, and R. Courtin 1989. The thermal structure of Titan's atmosphere. Icarus 80, 23-53.

Minard, R. D., P. G. Hatcher, R. C. Gourley, and C. N. Matthews 1998. Structural investigations of hydrogen cyanide polymers: New insights using TMAH thermochemolysis/GC-MS. Origins of Life Evol. Biosphere 28, 461-473.

Monks, P. S., P. N. Romani, F. L. Nesbitt, M. Scanlon, and L. J. Stief 1993. The kinetics of the formation of nitrile compounds in the atmosphere of Titan and Neptune. J. Geophys. Res. 98 (E9), 17115-17122.

Nava, D. F., M. B. Mitchell, and L. J. Stief 1986. The reaction H $+\mathrm{C}_{4} \mathrm{H}_{2}$ : absolute rate constant measurement and implication for atmospheric modeling of Titan. J. Geophys. Res. 91 (A4), 45854589 .

Opansky, B. J., and S. R. Leone 1996a. Low-temperature rate coefficients of $\mathrm{C}_{2} \mathrm{H}$ with $\mathrm{CH}_{4}$ and $\mathrm{CD}_{4}$ from 154 to 359 K. J. Phys. Chem. 100 (12), 4888-4892.

Podolak, M., and A. Bar-Nun 1979. A constraint on the distribution of Titan's atmospheric aerosol. Icarus 39, 272-276.

Rannou, P., M. Cabane, R. Botet, and E. Chassefière 1997. A new interpretation of scattered light measurements at Titan's limb. J. Geophys. Res. 102 (E5), 10997-11013.

Rannou, P., M. Cabane, E. Chassefière, R. Botet, C. P. McKay, and R. Courtin 1995. Titan's geometric albedo: role of the fractal structure of the aerosols. Icarus 118, 355-372.

Ricca, A., C. W. Bauschlicher, Jr., and E. Bakes 2001. A computational study of the mechanisms for the incorporation of a nitrogen atom into polycyclic aromatic hydrocarbons in the Titan haze. Icarus 154, $516-521$.

Sagan, C., B. N. Khare, W. R. Thompson, G. D. McDonald, M. R. Wing, J. L. Bafa, T. Dinh, and E. T. Arakawa 1993. Polycyclic aromatic hydrocarbons in the atmosphere of Titan and Jupiter. Astrophys. J. 414, 399.

Sagan, C., and W. R. Thompson 1984. Production and condensation of organic gases in the atmosphere of Titan. Icarus 59, 133-161.

Sagan, C., W. R. Thompson, and B. N. Khare 1992. Titan: A laboratory for prebiological organic chemistry. Acc. Chem. Res. 25 (7), 286-292.

Scatterwood, T. W., E. Y. La1, and B. M. Stone 1992. Titan aerosols. I. Laboratory investigations of shapes, size distributions, and aggregation of particles produced by UV photolysis of model Titan atmospheres. Icarus 99, 98-105.

Thompson, W. R., T. J. Henry, J. M. Schwartz, B. N. Khare, and C. Sagan 1991. Plasma discharge in $\mathrm{N}_{2}+\mathrm{CH}_{4}$ at low pressures: Experimental results and applications to Titan. Icarus 90, 57-73.

Thompson, W. R., and C. Sagan 1989. Atmospheric formation of organic heteropolymers from $\mathrm{N}_{2}+\mathrm{CH}_{4}$ : Structural suggestions for amino acid and oligomer precursors. Origins of Life 19, 503-504.

Toon, O. B., C. P. McKay, C. A. Griffith, and R. P. Turco 1992. A physical model of Titan's aerosols. Icarus 95, 24-53.

Toublanc, D., J. P. Parisot, J. Brillet, D. Gautier, F. Raulin, and C. P. McKay 1995. Photochemical 
modeling of Titan's atmosphere. Icarus 113, 2-26.

Vervack, R. J., Jr. 1997. Titan's upper atmospheric structure derived from Voyager ultraviolet spectrometer observations. PhD thesis, University of Arizona.

Wang, H., and M. Frenklach 1994. Calculations of rate coefficients for the chemically activated reactions of acetylene with vinylic and aromatic radicals. J. Phys. Chem. 98, 11465-11489.

Wong, A.-S., A. Y. Lee, Y. L. Yung, and J. M. Ajello 2000. Jupiter: Aerosol chemistry in the polar atmosphere. Astrophys. J. 534, L215-L217.

Yung, Y. L., M. Allen, and Pinto J. P. 1984. Photochemistry of the atmosphere of Titan: Comparison between model and observations. Astrophys. J. Supp. 55, 465-506. 